\title{
DESAFIOS PARA ENFERMAGEM NO ATENDIMENTO A OS PACIENTES IDOSOS COM DELIRIUM E COVID-19 EM UNIDADES DE CUIDADOS CRÍTICOS
}

\author{
Margarita Ana Rubin Unicovsky' \\ ORCID: 6161792036363731 \\ Michelle Santarem' \\ ORCID: 0000-0002-7046-7007
}

'Universidade Federal do Rio Grande do Sul (UFRGS). Porto Alegre, Rio Grande do Sul, Brasil.

Autor Correspondente: Margarita Ana Rubin Unicovsky

E-mail: mar.u@terra.com.br

Como citar:

Unicovsky MAR, Santarem M. Desafios para enfermagem no atendimento aos pacientes idosos com delirium e covid-19 em unidades de cuidados críticos. In: Santana RF. Enfermagem gerontologica no cuidado do idoso em tempos da COVID 19. 2.ed.rev. Brasilia, DF: Editora ABEn; 2020. p.61-65. (Serie Enfermagem e Pandemias, 1). https://doi.org/10.51234/aben.20.e01.c10

\section{INTRODUÇÃO}

Desde dezembro de 2019, a China relatou casos de pneumonias graves associadas ao novo vírus chamado de coronavírus ou SARS-CoV2, desde lá esse vírus vem devastando os mais diversos sistemas de saúde da China, Europa e Estados Unidos, entre outros países, tornando-se um problema de saúde pública global, este vírus vem atingindo principalmente a população de risco e os idosos estão entre eles. No final de janeiro de 2020, a Organização Mundial de Saúde emitiu um alerta sobre o surgimento de uma nova epidemia viral relacionado ao SARS-CoV2. Indicadores ainda estão sendo estabelecidos, mas sabidamente pelos casos confirmados, a taxa de mortalidade geral vem crescendo substancialmente, com dezenas de casos a cada dia em inúmeros lugares do mundo, e principalmente entre os idosos ${ }^{(1-2)}$.

O aumento gradual da expectativa de vida, a queda das taxas de natalidade e mortalidade, impulsionou o envelhecimento acelerado da população brasileira. Estes fatores contribuíram para a busca de usuários aos Serviços de Saúde por descompensação e deterioração clínica devido ao aumento substancial de complicações decorrentes de doenças crônicas não transmissíveis, contribuindo para o aumento de processos de atendimento nas mais diversas instituições de saúde de uma forma geral.

A população idosa utiliza os recursos da saúde de forma aumentada em relação as demais faixas etárias, necessitando de uma abordagem multidimensional e multiprofissional com o intuito de atingir um objetivo de vida funcional, independente e acima de tudo com qualidade. A internação hospitalar pela a COVID-19 pode favorecer o surgimento de complicações e incapacidades nessa população como o delirium ${ }^{(3-4)}$

Políticas institucionais voltadas para o diagnóstico, tratamento e prevenção de condições de saúde-doença prevalentes na população idosa contribuem substancialmente 
para atingir objetivos terapêuticos e minimizar as complicações e sequelas de natureza iatrogênica. Deve-se ressaltar que, em até $30 \%$ dos pacientes idosos que chegam às unidades de tratamento intensivo, o delirium é um sintoma que anuncia a presença de uma condição subjacente que acarreta risco à vida deste paciente. As taxas de mortalidade entre os pacientes hospitalizados com delirium têm uma variação de 22 a $76 \%$. ${ }^{(5)}$

\section{OBJETIVOS}

Reflexão teórica sobre a importância de identificar as características clínicas, os fatores de risco de delirium no paciente idoso.

\section{MÉTODO}

Estudo de natureza reflexiva, em pacientes idosos críticos, com delirium elaborada num cenário de ainda poucas evidências científicas sobre a COVID-19.

\section{RESULTADOS}

\section{DELIRIUM}

A origem da palavra delirium é atribuída ao latim deliro-delirare, de-lira, que significava "estar fora do lugar". É uma alteração cognitiva definida por início agudo, de curso flutuante, distúrbios da consciência, atenção, orientação, memória, pensamento, percepção e comportamento. ${ }^{(6)}$ Pode ocorrer na forma hiperativa, hipoativa ou mista e pode acometer mais de $50 \%$ de idosos hospitalizados. ${ }^{(7)}$ É considerada emergência geriátrica e se relaciona com períodos mais prolongados de hospitalização, com maiores taxas de mortalidade e com maior taxa de institucionalização. Acomete, comumente, pacientes com maior grau de fragilidade e maior número de comorbidades.

O delirium pode ser derivado de várias causas, como doença física, intoxicação (medicamentosa ou alcoólica), desidratação/desnutrição, traumatismos, infecções, distúrbios metabólicos, desordens do SNC, neoplasias, fármacos e uma considerada fundamental a mudança de ambiente.

A incidência eleva-se com a idade, déficit cognitivo, fragilidade, gravidade da doença e comorbidades. Setores de emergência, unidades de cuidados intensivos e setores de pós-operatório apresentam as maiores taxas de delirium. ${ }^{(8)}$ No entanto, apesar de ser uma condição comum a estes pacientes, ainda é subdiagnosticada e subnotificada, apesar de apresentar prevalência de 10 a 16\% já na admissão. Os setores citados são locais estratégicos para o diagnóstico e manejo precoce dessa condição desde que não seja ignorada pela equipe multiprofissional. ${ }^{(9)}$

\section{CARACTERISTICAS CLÍNICAS DO PACIENTE IDOSO COM DELIRIUM E COVID-19}

O diagnóstico de delirium, atualmente, continua sendo feito por meio de uma observação à beira do leito. Assim, conhecer suas características clínicas é crucial para um diagnóstico assertivo. ${ }^{\left({ }^{8}\right)}$ As manifestações clínicas do delirium caracterizam-se por apresentar déficits cognitivos que normalmente ocorrem sob forma de déficits globais ou múltiplos na cognição, incluindo desorientação, déficits de memória e distúrbio de linguagem. Ocorre dificuldade de concentrar-se, sustentar e deslocar a atenção, bem como ocorre turvação da consciência, com clareza reduzida de sensibilização para o ambiente. Ocorre sonolência diurna, normalmente, insônia noturna, sono fragmentado ou reversão completa do ciclo do sono. Podem se apresentar hiperativos, marcados pela agitação e vigilância ou hipoativos, marcados pela letargia e diminuição do nível de atividade motora. Os sintomas têm início, geralmente, de modo agudo, no entanto podem ser relativamente insidiosos, precedidos por diminuição da concentração, irritabilidade e insônia. ${ }^{(7-8)}$ 


\section{COVID-19}

Os sinais e sintomas clínicos do novo coronavírus são principalmente respiratórios, semelhantes a um resfriado. Podem, também, causar infecção do trato respiratório inferior, como as pneumonias. Os principais são sintomas são: febre acima de $37^{\circ} \mathrm{C}$, tosse seca ou com secreção, dificuldade respiratória e cansaço. Outros sintomas também podem estar presentes, como: dor de garganta, falta de paladar, coriza, obstrução nasal e diarreia. A fadiga, a diarreia, hipertermia, infecções e o cansaço podem estar presentes no delirium. ${ }^{(1-2)}$

\section{FATORES DE RISCO PARA DELIRIUM}

São elementos intrínsecos ou extrínsecos que aumentam a possibilidade de o paciente desenvolver delirium. Deve-se ter cuidado para não os confundir com as causas do distúrbio. O delirium pode se apresentar em cenários distintos, sendo de origem multifatorial. Podemos classificar esses fatores em dois grupos: predisponentes e precipitantes. Os fatores de risco predisponentes são inerentes aos próprios pacientes e suas enfermidades e são raramente ou nunca modificáveis. São também, chamados de fatores de vulnerabilidade, alguns exemplos desses fatores: doença orgânica crônica e grave, síndrome demencial de qualquer etiologia, doença cerebral difusa, desnutrição, sono e audição, depressão. Os fatores precipitantes estão relacionados à intensidade da doença, à terapêutica empregada e ao ambiente onde o paciente está situado, podendo ser modificáveis. ${ }^{(7-11)}$

Estatisticamente os fatores de risco para o COVID-19 estão relacionados a pessoas com 60 anos ou mais, portadores de doenças crônicas: hipertensão, diabetes, doenças cardíacas e/ou respiratórias, histórico de câncer e de transplantes, uso de imunossupressores. ${ }^{(9)}$

O papel do enfermeiro é preponderante na avaliação do risco de Delirium na unidade de cuidados críticos, para tal dispomos, de instrumentos com o propósito de detectar alterações comportamentais e/ou de consciência, os mais utilizados são Intensive Care Delirium Screening Scale Checklist (ICDSC) e o Confusion Assessment Method for Intensive Care Units CAM-UCl. Esse último, encontra-se traduzido e validado para o Brasil, instrumento com sensibilidade e pode ser aplicado pelos enfermeiros na prática clínica. A avaliação cognitiva como os dados do Mini-Exame do Estado Mental (MEEM) auxiliam na tomada de decisão do enfermeiro, no entanto se houver limitações de sua aplicação no ambiente de cuidados críticos pode se buscar dados anteriores.

\section{INTERVENÇÕES DE ENFERMAGEM}

A equipe de Enfermagem tem papel fundamental perante o cuidado ao paciente idoso em Delirium e na Pandemia do COVID-19. O pessoal atuante na linha de frente desses desafios devem estar treinados para o reconhecimento precoce dos sinais e sintomas e munidos de conhecimento científico, baseado em evidências juntamente com outras habilidades como a destreza no atendimento, isso desenvolverá uma assistência segura, com qualidade, observando os princípios da ciência humanizada. ${ }^{(12)}$ Implementar um plano de cuidados de enfermagem ao paciente idoso com delirium acometidos da COVID-19.

Ações de enfermagem que visem o favorecimento da manutenção do equilíbrio sensorial são uteis no controle do delirium. Como iluminação, controle do ruído, orientação no tempo e espaço. Nesse sentido, o enfermeiro necessita promover um espaço de cuidado minimizador de défices sensoriais, como estimular sempre que possível, o uso dos óculos e órteses auditivas.

Promover um sono adequado também colabora na minimização do delirium, ocorrem taxas de $61 \%$ de privação de sono nas UTI, muito em consequência do ruído e da luminosidade intensa, aspectos fisiológicos e medicamentos. Atividades como permitir períodos de sono contínuo durante a noite, evitar a inversão do ciclo de sono, reduzir o ruído e organizar horários de procedimentos de enfermagem podem facilitar o equilíbrio sensorial e a manutenção de um ambiente seguro. Intervenções não farmacológicas como musicoterapia, a massagem, o relaxamento e a avaliação do controle da dor são benéficas para diminuir o risco de delirium. ${ }^{(11,14,15)}$ 
Outra ação de enfermagem importante é a mobilização precoce do idoso deve ser fomentada a atividade o mais precoce possível, isso melhora o sono e a dor reduzindo assim o risco de confusão mental, como também outros agravos como o risco de lesão por pressão. ${ }^{(14,15)}$ As técnicas válidas de enfermagem neste âmbito que identificamos, remetem-se a estimular e ensinar movimentos no leito, a alternância de decúbitos ou conforme tolerado, a encorajar a deambulação.

Um estudo estimou que a chance de um paciente da UTI ficar contido é 23,4 vezes maior que a chance de um paciente que não está na UTI, e em pacientes contido a chance de desencadear o delirium é 2,82 vezes. ${ }^{(16)}$ Portanto, a contenção mecânica utilizada em sua maioria para evitar quedas e prevenir a retirada de dispositivos invasivos (sondas, cateteres e tubos) pode quando utilizada de forma contínua sem avaliação do delirium ser a causa da agitação e agressividade dos pacientes idosos e conferir em um des-cuidado. Portanto, a contenção mecânica deve ser evitada pois pode ser fator desencadeante além de promover desconforto ao paciente.

Em suma, as medidas não farmacológicas para a prevenção e controle do delirium devem ser a primeira etapa do cuidado dos enfermeiros, manter a mobilidade, uma alimentação adequada, uso das próteses dentárias, manter a higiene/hidratação oral, avaliar sinais de constipação ou retenção urinária. Como também, controlar a aceitação a medicação sedativa, e de controle da dor colaborando no ajuste da dose ideal.

Sabemos que nesse momento da Pandemia da COVID-19 há restrições quanto a presença dos familiares/ pessoas significativas, no entanto medidas que possibilite um canal de comunicação entre idoso e familiar pode beneficiar a orientação dos pacientes idosos, e suporte e apoio aos familiares, proporcionando sensação de bem-estar e qualidade do cuidado.

\section{CONSIDERAÇÕES FINAIS}

Ao analisar um ambiente gerador de estressores, como a Unidade de Tratamento Intensivo e as emergências, deve-se ter em mente a grande demanda de trabalho e sobrecarga dos trabalhadores que se encontra neste cenário. Vale ressaltar que é de extrema relevância repensar o atendimento prestado pela equipe ao paciente, durante a internação nestas unidades e definir que é imprescindível a humanização no cuidado, a comunicação com os familiares, a educação permanente, bem como a importância do papel da enfermagem para a identificação precoce do delirium e a utilização de medidas de comunicação entre profissionais e pacientes que estão também em situações críticas como o COVID-19.

Essas condutas, que podem ser protocolos, com o intuito de sistematizar às boas práticas, com destaque para a escuta do paciente e a preservação da sua autonomia. Nesses casos, muitas vezes, a comunicação entre profissionais de saúde e pacientes é falha e que, além disso, gera danos como o desenvolvimento de depressão e ansiedade causada pelo isolamento. Cabe à equipe de enfermagem estar atenta às alterações clinicas e também aos seus fatores de risco, podendo intervir de forma ágil por meio de medidas com vistas a prevenção desse desfecho.

\section{AGRADECIMENTO}

Ao Departamento Científico de Enfermagem Gerontológica da ABEn Nacional.

\section{REFERÊNCIAS}

1. Bouadma, Lila et al. Severe SARS-CoV-2 infections: practical considerations and management strategy for intensivists. Intensive care medicine, p. 1-4, 2020.

2. Corman VM, Landt O, Kaiser M, Molenkamp R, Meijer A, Chu DK, Bleicker T, Brunink S, Schneider J, Schmidt ML, Mulders DG, Haagmans BL, van der Veer B, van den Brink S, Wijsman L, Goderski G, Romette JL, Ellis J, Zam bon M, Peiris M, Goossens H, Reusken C, Koopmans MP, Drosten C (2020) Detection of 2019 novel coronavirus (2019-nCoV) by real-time RT-PCR. Euro surveillance 25:3 
3. Araújo JD de. Polarização epidemiológica no Brasil. Epidemiol. Serv. Saúde [periódico na Internet]. 2012 Dez [citado em 2017 Jun 08]; 21 ( 4 ): 533-538. Disponível em: http://scielo.iec.pa.gov.br/scielo. php?script=sci_arttext\&pid=S1679-49742012000400002\&lng=pt.

4. Duarte EC, Barreto SM. Transição demográfica e epidemiológica: a Epidemiologia e Serviços de Saúde revisita e atualiza o tema. Epidemiol. Serv. Saúde [periódico na Internet]. 2012 Dez [citado em 2017 Maio 15]; 21 ( 4 ): 529-532. Disponível em: http://scielo.iec.pa.gov.br/scielo.php?script=sci_arttext\&pid=S1679-49742012000400001\&lng=pt.

5. Ceratti RN; Teixeira TO. Delirium no paciente Idoso. Porto Alegre: Artmed Panamericana; 2016. p. 65-87.

6. Berrios GE. Delirium e confusão mental no século XIX: uma história conceitual. Rev.Latinoam Psicopatol Fund. 2019 Mar, 14(1): 166-89.

7. Fernandes MB; Zalli M; Benghi R; Felipe Sparrenberger. Geriatria para clínicos: medicina aplicada à terceira idade. Rio de Janeiro: Revinter; 2019.

8. Inouye SK.Delirium in older persons. N Engl J Med. 2018 Mar;354(11):1157-65.

9. American Psychiatric Association. Diagnostic and statiscal manual of mental disorders (DSM-5) 5nd ed. Arlington:APA; 2019.

10. Salluh JIF; Pandharipande P. Prevenção do delirium em pacientes críticos: um recomeço? Revista Brasileira de Terapia Intensiva, 24:1, p. 1-3, 2012. Available from: . Acesso em: 11 jun. 2012.

11. Pereira J, Barradas F, Sequeira R, Marques M, Batista M, Galhardas M, et al. Delírium no doente crítico: fatores de risco modificáveis pelos enfermeiros. Rev Enferm Referência. Maio; IV(9):29-36. 2016.

12. Baeta, KF et al. Protocolo de Tratamento do Novo Coronavirus. (2019-nCov). Ministério da Saúde, 2020.

13. Xavier JAD, Alves FLB. Entenda sobre o coronavirus- Epidemiologia e precauções Journal of Infection Control, v.9,n.1, 2020.

14. Oosterhouse K, Vincent C, Foreman M, Gruss V, Corte C, Berger B. Intensive Care Unit Nurses' Beliefs About Delirium Assessment and Management. AACN Adv Crit Care. Outubro de 2016;27(4):379-93.

15. Faustino T, Pedreira L, Freitas Y, Silva R, Amaral J. Prevention and monitoring of delirium in older adults: an educational intervention. Rev Bras Enferm [Internet]. 2016 [citado 22 de Junho de 2017];69(4):725-32.

16. Souza LMS, Santana RF, Capeletto CSG, Menezes AK, Delvalle, R. (2019). Fatores associados à contenção mecânica no ambiente hospitalar: estudo transversal. Revista da Escola de Enfermagem da USP, 53, e03473. Epub June 13, 2019.https:// dx.doi.org/10.1590/s1980-220x2018007303473 